\title{
Nanozymes as Enzyme Inhibitors
}

This article was published in the following Dove Press journal:

International Journal of Nanomedicine

\author{
Yaling Huang' \\ Jian Jiang' \\ Yanqiu Wang' \\ Jie Chen' \\ Juqun $X i^{1,2}$
}

'Institute of Translational Medicine, Department of Pharmacology, School of Medicine, Yangzhou University, Yangzhou, Jiangsu, 22500I, People's Republic of China; ${ }^{2}$ Jiangsu Key Laboratory of Integrated Traditional Chinese and Western Medicine for Prevention and Treatment of Senile Diseases, Yangzhou, Jiangsu, 22500I, People's Republic of China
Correspondence: Juqun $\mathrm{Xi}$ Institute of Translational Medicine, Department of Pharmacology, School of Medicine, Yangzhou University, Yangzhou, Jiangsu, 22500I, People's Republic of China

Tel +86 05I4-87978804

Fax $+8605 \mid 4-87341733$

Email xijq@yzu.edu.cn
Abstract: Nanozyme is a type of nanomaterial with intrinsic enzyme-like activity. Following the discovery of nanozymes in 2007, nanozyme technology has become an emerging field bridging nanotechnology and biology, attracting research from multidisciplinary areas focused on the design and synthesis of catalytically active nanozymes. However, various types of enzymes can be mimicked by nanomaterials, and our current understanding of nanozymes as enzyme inhibitors is limited. Here, we provide a brief overview of the utility of nanozymes as inhibitors of enzymes, such as R-chymotrypsin (ChT), $\beta$-galactosidase ( $\beta$-Gal), $\beta$-lactamase, and mitochondrial F0F1-ATPase, and the mechanisms underlying inhibitory activity. The advantages, challenges and future research directions of nanozymes as enzyme inhibitors for biomedical research are further discussed. Keywords: nanozyme, R-chymotrypsin inhibitor, $\beta$-galactosidase inhibitor, $\beta$-lactamase inhibitor, mitochondrial F0F1-ATPase inhibitor

\section{Introduction}

In the early 1960s, the Japanese scientist Umezawa put forward the concept of "enzyme inhibitor", a compound that specifically acts on certain groups of the enzyme, thereby affecting the active center and leading to a decline in the rate of enzymatic reaction. ${ }^{1}$ Enzyme inhibitors have been shown to play important roles in various biomedical and clinical areas, from biometrics to treatment of numerous diseases including diabetes, ${ }^{2}$ emphysema, ${ }^{3}$ Alzheimer's disease, ${ }^{4}$ and even cancer. ${ }^{5}$ Although the existence of enzyme inhibitors in organisms is as widespread as enzymes, less than $10 \%$ plant species have been tested for any type of biological activity. At present, enzyme inhibitors are mainly derived from plants, microorganisms and chemical synthesis. ${ }^{6}$ However, screening for plant- or microorganismderived enzyme inhibitors often produces a large number of "false-positive" results, which interferes with the identification of true active components ${ }^{7}$ and enzyme inhibitors obtained through chemical synthesis inevitably display highly selective inhibitory activity on one or a few types of enzymes. ${ }^{8,9}$ Moreover, high concentrations of small-molecule inhibitors are usually required to maintain their bioactivities, inevitably resulting in non-targeted effects and toxicity. ${ }^{10}$ Therefore, development of inhibitors with a broad spectrum of activity remains a hot topic for future research.

Nanozymes are a class of nanomaterials with intrinsic enzyme-mimicking characteristics, mainly including peroxidase-, oxidase-, catalase-, and superoxide dismutase-like activities. ${ }^{11}$ Compared with natural enzymes, nanozymes are more stable at a wider range of $\mathrm{pH}$ and temperatures in addition to several advantages, such as low cost, high stability and easy large-scale preparation. ${ }^{12}$ The multi- 
enzyme activities of nanozymes have been successfully applied in numerous fields, such as biosensor development, cancer treatment, environmental protection, and antimicrobial therapy. ${ }^{13-16}$ Unexpectedly, in addition to their biocatalytic functions, nanozymes have been shown to selectively bind different enzymes and inhibit their activities, further extending their potential biomedical applications.

In this review, we have focused on the nanomaterials that worked as both nanozymes and enzyme inhibitors, and discussed their properties, inhibitory mechanisms, and novel applications. The current status and future perspectives are summarized, with the aim of providing novel insights that could aid in improving the design of new enzyme inhibitors and better understanding the biological activities of nanozymes.

\section{Nanozymes as R-Chymotrypsin Inhibitors}

R-chymotrypsin (ChT) was first identified as a structured serine protease by Blow. ${ }^{1}$ Among the multiple known serine proteases, ChT is considered an excellent system for exploring protein surface recognition to achieve direct inhibition of active sites due to its geometry and extensive enzymatic properties. ${ }^{17}$ In this regard, small-molecule inhibitors, such as porphyrin derivatives and cyclodextrin dimers, have been recently designed as receptors for the interaction domain of the protein periphery surface to regulate enzyme behavior. ${ }^{18,19}$ More recently, nanomaterials have attracted significant attention as suitable and promising candidates to achieve protein surface recognition owing to two unique properties not displayed by small-molecule inhibitors: 1) large receptor surface areas that promote efficient protein surface contact and binding and 2) easy fabrication to provide useful and functionalized structures. ${ }^{20}$

To obtain functional nanomaterials similar to protein surfaces, You et $\mathrm{al}^{21}$ constructed carboxylic acidfunctionalized gold nanoparticles with different L-amino acids (Figure 1A) and investigated their effects on the rate of ChT-catalyzed N-succinyl-L-alanine-p-nitroanilide (SPNA) hydrolysis. Gold nanoparticles are known to possess peroxidase-, oxidase-, and glucose oxidase-like activities. $^{22}$ In the presence of negatively charged amino acid-modified gold nanoparticles, such as NP_Gly, NP_LGln, NP_L-Asn, NP_L-Glu, NP_L-Asp, NP_L-Phe, NP_L-Leu, NP_L-Met, NP_L-Val, and NP_L-Ala, the rate of ChT-catalyzed SPNA hydrolysis was reduced, supporting a significant inhibitory effect on ChT activity. In contrast, gold nanoparticles modified with positively charged amino acids (NP_L-Arg) exerted no obvious effects on ChT activity (Figure 1B). These results indicate that complementary electrostatic interactions between nanoparticles and ChT provide the main driving force for the formation of high-affinity complexes. The ChT active site is surrounded by cationic residues, which favorably bind negatively charged gold nanoparticles. More importantly, in a study on structural stability of proteins, the circular dichroism (CD) spectrum of ChT was completely dependent on the amino acid side-chains of nanoparticles. In the presence of gold particles with a hydrophobic amino acid side-chain, NP-L-Leu, almost no changes in the CD spectrum of ChT were observed, while nanoparticles with hydrophilic L-Asn and L-Asp side-chains induced varying degrees of $\mathrm{CD}$ spectral changes (Figure 1C). To understand the denaturation kinetics of $\mathrm{ChT}$ in the presence of nanoparticles, a more sensitive steady-state fluorescence spectroscopy method was used to analyze the characteristic fluorescence of tryptophan residues in ChT. The degree of denaturation of $\mathrm{ChT}$ is reflected by differences in fluorescence shift values. Notably, after incubation with nanoparticles for $24 \mathrm{~h}$, hydrophilic NP_L-Asp induced about 90\% ChT denaturation while hydrophobic NP_L-Leu only induced 20\% denaturation (Figure 1D). A reasonable explanation for this finding is that the side-chains of hydrophobic amino acids only interacted with hydrophobic plaques on the ChT surface, preserving the protein structure in the same way as natural protein-protein interactions, while hydrophilic L-Asn and L-Asp induced ChT degeneration by competing for hydrogen bonds or destroying salt bridges. It suggested that the carboxylate function facilitated the denaturation process, and the formation of competitive hydrogen bonding might destabilize the $\alpha$ helices in ChT and disrupt their secondary structure. Thus, the surface properties of nanomaterials play a key role in controlling the regulation of ChT association/dissociation/stability/denaturation. To further improve the versatility of surface receptors, it is possible to introduce extra ligand functionality, such as carboxylic acid recognition elements, to nanoparticle interfaces.

ChT, a representative serine protease, displays a characteristic structure. As shown in Figure 2A, the active site is surrounded by a positively charged residue loop while some hydrophobic "hot spots" are distributed on the surface. Owing to this structural feature, 
A
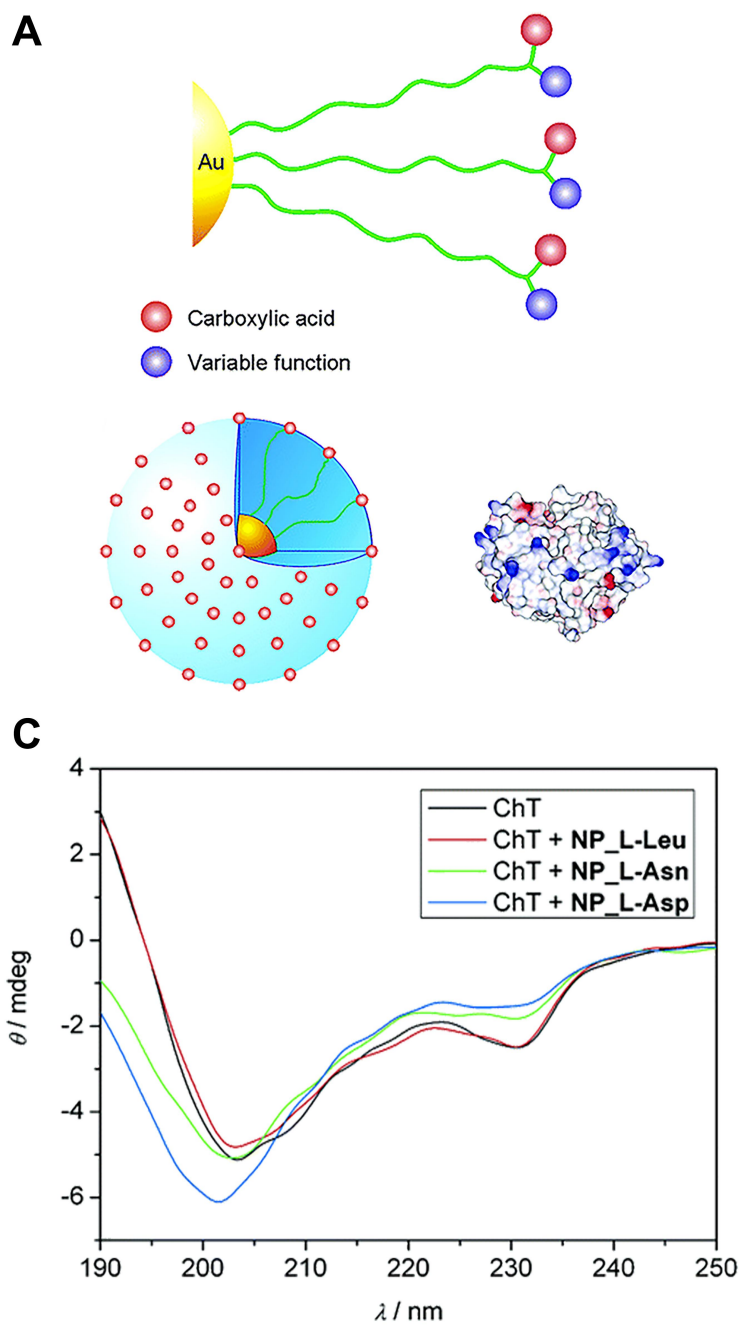

B

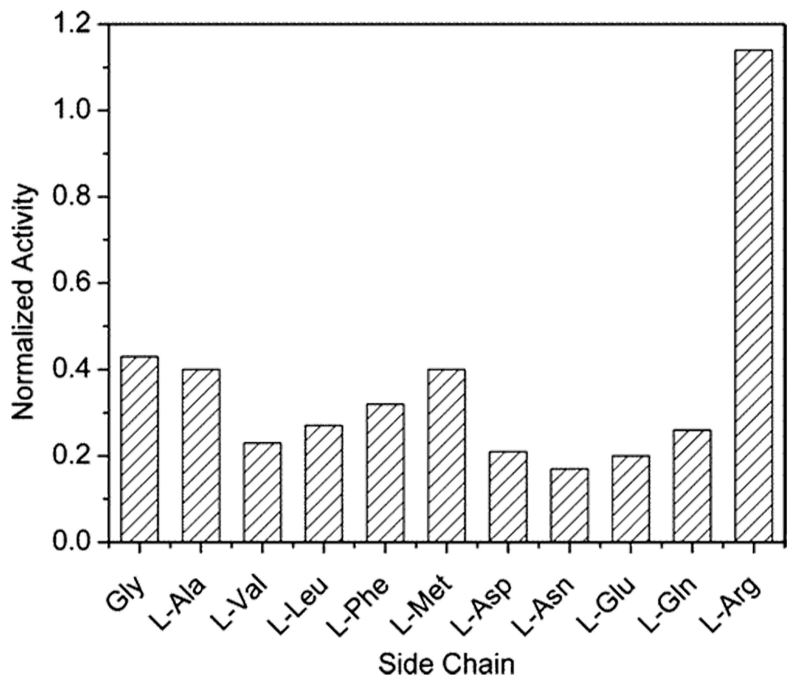

D

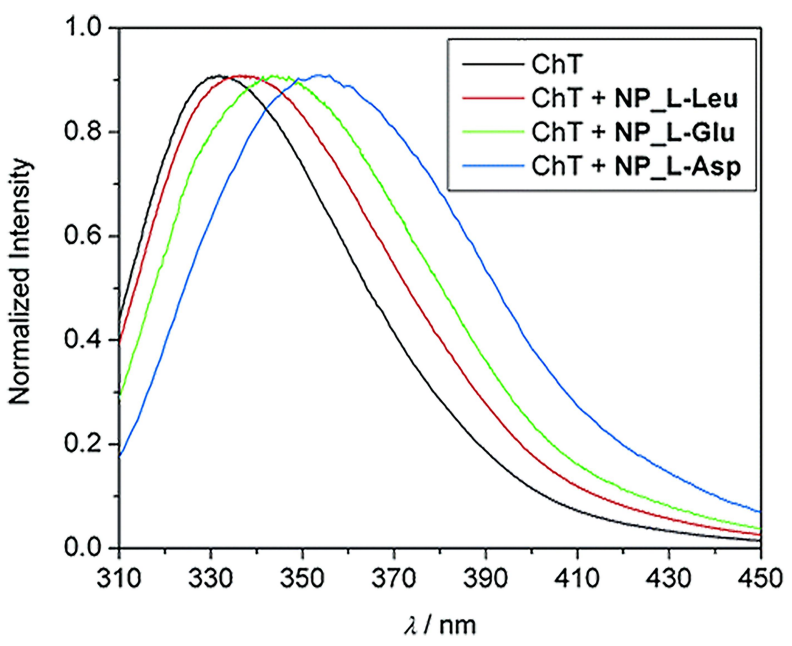

Figure I (A) Amino acid-decorated cluster surface that consists of carboxylic acid recognition elements as well as extra functions for perturbation. The relative sizes of amino acid-functionalized gold nanoparticles and ChT. The surface of ChT is patterned with the electrostatic surface potential, showing basic and acidic domains on protein surface. (B) Normalized activity of ChT with nanoparticles bearing various amino acid side chains. (C) Circular dichroism spectra of ChT and ChT with nanoparticles after 24 $\mathrm{h}$ incubation. The weak CD signal of the nanoparticles has been subtracted from that of the complex. (D) Fluorescence spectra of ChT and ChT with nanoparticles after 24 h incubation. Reprinted with permission from You CC, De M, Han G et al Tunable inhibition and denaturation of $\alpha$-Chymotrypsin with amino acid-functionalized gold nanoparticles. J Am Chem Soc. 2005; 127(37): 12873-1288I. Copyright (2005) American Chemical Society. ${ }^{21}$

electrostatic interactions play an important role in enzyme-substrate binding (Figure 2B). Studies by You et $\mathrm{al}^{23}$ demonstrated that amino acid (carboxylic acid group)-functionalized gold nanoparticles form supramolecular complexes with ChT (ChT-nanoparticle complexes) that display different enzymatic kinetics for three SPNA-derived substrates with diverse charge characteristics (cationic SPNA (S1), neutral SPNA (S2) and anionic SPNA (S3); Figure 2C). After the formation of ChT-nanoparticle complexes, the substrate-binding ability of $\mathrm{ChT}$ depends on electrostatic interactions between the amino acid monolayer and various substrates. In this case, the SPNA hydrolysis rate was in the order
$\mathrm{S} 1>\mathrm{S} 2>\mathrm{S} 3$. Compared with $\mathrm{S} 1$, the specificity constant of ChT for S3 was significantly decreased due to the strongest electrostatic repulsion between the monolayer and substrate (Figure 2D). These results indicate that the amino acid-functionalized gold nanoparticles as nanoreceptors regulate rather than simply inhibit ChT activity. The inhibitory activity of nanoparticles on enzymes is distinct from traditional competitive and noncompetitive mechanisms, ${ }^{24}$ which is not only for the preparation of enzyme regulators based on surface recognition provides an effective scaffold, but also has broad application prospects in protein stability, modification and delivery. 
A

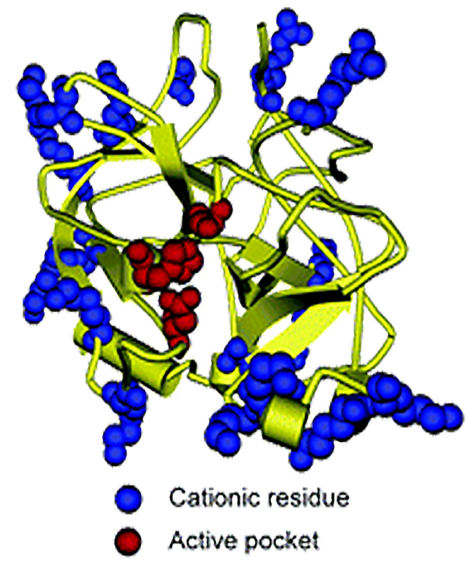

C

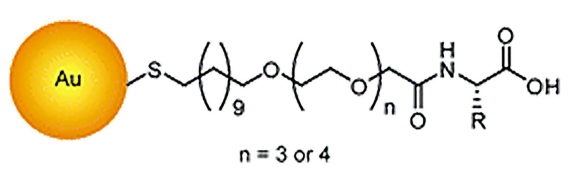<smiles>[Y]CCOCCOCCNC(=O)CCC(=O)N[C@@H](Cc1ccccc1)C(=O)Nc1ccc([N+](=O)[O-])cc1</smiles>

$\mathrm{R}^{1}=-\mathrm{NH}_{3}^{+} \quad \mathrm{S1}$

$\begin{array}{ll}-\mathrm{OH} & \mathrm{S2} \\ -\mathrm{OCH}_{2} \mathrm{CO}_{2} & \mathrm{~S} 3\end{array}$
B
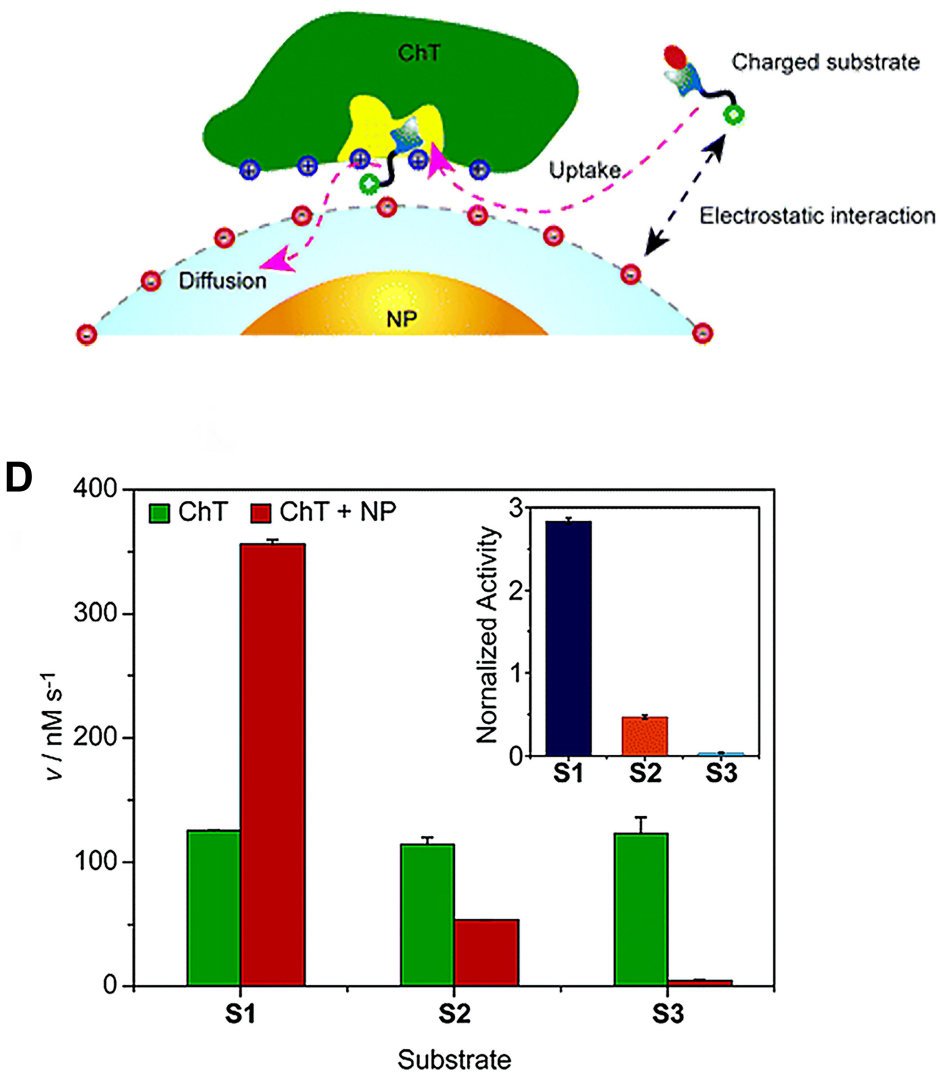

Figure 2 (A) Molecular structure of R-chymotrypsin. (B) Schematic representation of monolayer-controlled diffusion of the substrate into and the product away from the active pocket of nanoparticle bound ChT. (C) Chemical structure of amino-acid-functionalized gold nanoparticles and SPNA-derived substrates. (D) Generation rate (V) of 4-nitroaniline from different substrates under catalysis by ChT or ChT-nanoparticle complex. Inset shows the normalized activity of ChT-NP complex to ChT toward different substrates. Reprinted with permission from You CC, Agasti SS, De M et al Modulation of the catalytic behavior of $\alpha$-Chymotrypsin at monolayer-protected nanoparticle surfaces. J Am Chem Soc. 2006;128(45):I46I2-14618. Copyright (2006) American Chemical Society. ${ }^{23}$

Graphene oxide (GO) has been reported as a nanozyme possessing peroxidase-like activity. ${ }^{25}$ Furthermore, GO can act as an artificial ChT inhibitor due to unique properties, such as surface functionality, large surface area to mass ratio, and flexibility. De et $\mathrm{al}^{26}$ introduced carboxylate groups into native GO, which bound the cationic surface residues of $\mathrm{ChT}$ and simultaneously inhibited catalytic behavior towards anionic substrates (Figure 3A). Further evaluation of the effect of GO on ChT revealed that complete inhibition was achieved at a GO concentration of 20 $\mu \mathrm{g} / \mathrm{mL}$ (Figure 3B). Compared with other reported artificial ChT inhibitors, GO exerted the highest inhibitory effect (Figure 3C). More importantly, receptor interaction was highly biocompatible and the secondary structure of the protein maintained for a longer time period, as evident from fluorescence and CD spectra (Figure 3D). This high efficiency was attributed to the flexibility of the monolayer of GO, which facilitated adaptation to the surface curvature of the protein. The GO monolayer membrane could bind in a firm and compatible manner to the ChT surface, and the presence of hydrophobic aromatic groups in GO enhanced its affinity to hydrophobic "hot spots" around the active sites of ChT. Therefore, modification of GO with various active biomolecules could expand its biological applicability as an effective inhibitor with higher specificity and selectivity. ${ }^{27}$

\section{Nanozymes as $\beta$-Galactosidase $(\beta-$ Gal) Inhibitors}

Similar to ChT, $\beta$-galactosidase ( $\beta$-Gal) is a typical proteolytic enzyme that plays a crucial role in catalyzing hydrolysis of lactose to galactose. ${ }^{28}$ Upregulation of $\beta$ Gal is usually related to the occurrence of primary ovarian cancer and cell aging, and $\beta$-Gal inhibitors have been 
A

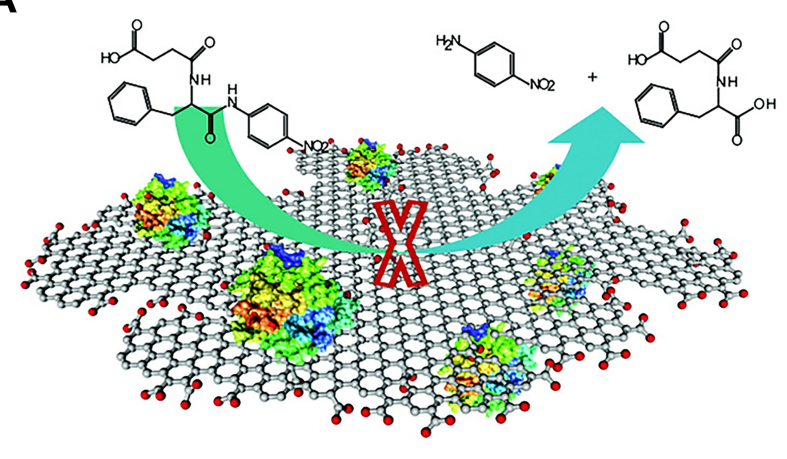

C

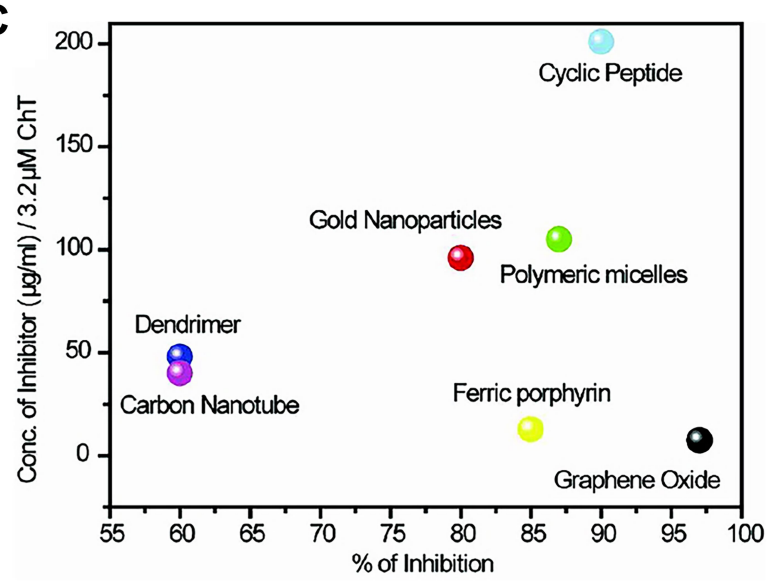

B

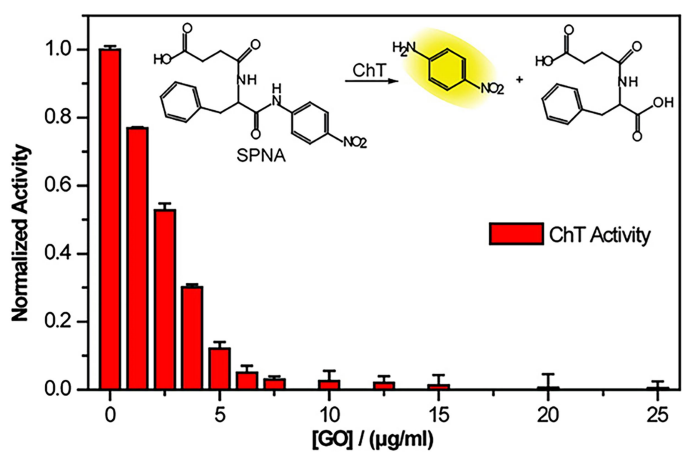

D
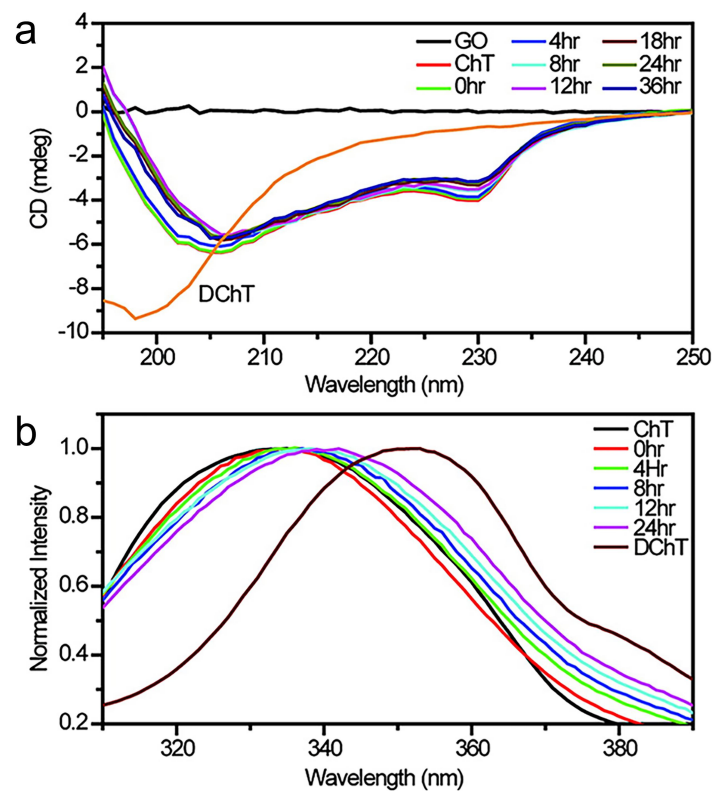

Figure 3 (A) Schematic diagram of GO inhibition $\mathrm{ChT}$ principle. (B) Activity of $\mathrm{ChT}$ plotted as a function of $\mathrm{GO}$ concentration in sodium phosphate buffer (pH 7.4) using SPNA as a substrate. The activities were normalized to that of ChT. (C) Degrees of inhibition and relative concentrations of various inhibitors used for altering the ChT activity. The right-bottom corner represents the most efficient inhibitor. (D(a)) CD spectra and (b) Tryptophan fluorescence of ChT with GO at different times. Reprinted with permission from De M, Chou SS, Dravid VP. Graphene oxide as an enzyme inhibitor: Modulation of activity of $\alpha$-Chymotrypsin. J Am Chem Soc. 201 I; 133(44):17524-17527. Copyright (201I) American Chemical Society. ${ }^{26}$

developed for application in clinical diagnosis of a number of diseases. ${ }^{29}$

Given the diversity of enzyme inhibitors, the development of novel nanoparticle inhibitors with unconventional structures has become a focus of research direction in recent years. ${ }^{30}$ The biocatalytic inhibitory activities of these new inhibitor types strongly depend on shape effects due to their diverse geometries. Earlier reports have shown that $\mathrm{ZnO}$ NPs with peroxidase activity have potential shape regulation capacity. ${ }^{31} \mathrm{Cha}$ and co-workers fabricated three types of zinc oxide nanoparticles $(\mathrm{ZnO}$ $\mathrm{NP}$ ) with different geometries by altering the shape and surface chemistry, including hexagonal nanopyramids, nanoplates and nanospheres (Figure 4A-C), and systematically compared the inhibitory effects of the different $\mathrm{ZnO}$ NPs on catalytic capacity of $\beta$-Gal. Their results showed that enzyme activity gradually decreased with increasing concentrations of nanopyramids and nanoplates but remained unchanged for all concentrations of nanospheres (Figure 4D-F). Moreover, relative to nanoplates, sharper apexes and edges of $\mathrm{ZnO}$ nanopyramids resulted in a higher degree of geometrical matching with the enzyme surface around the active center, thus inducing the strongest inhibitory effects. Therefore, in addition to hydrogen bonding and Vender Waals forces, molecular shape-dependent inhibitory behavior is responsible for weakening of the binding affinity of the substrate to the active site. 
A

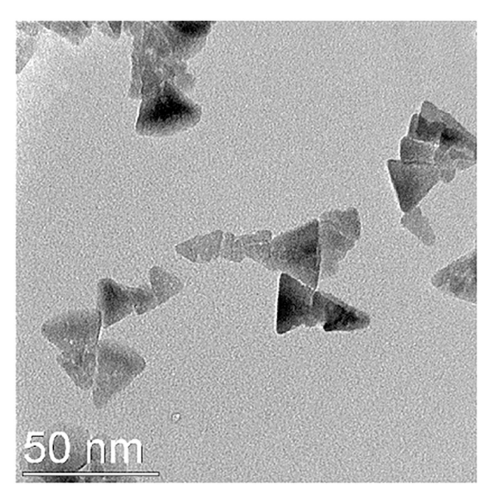

D

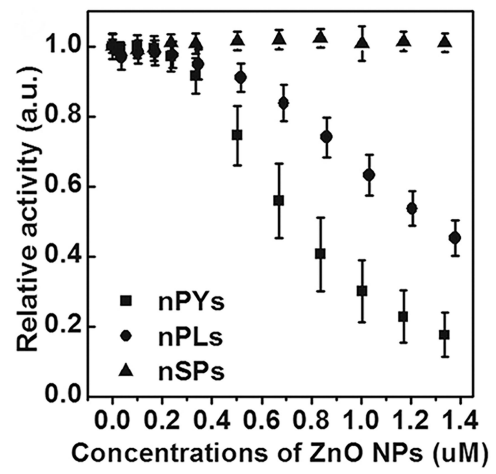

B

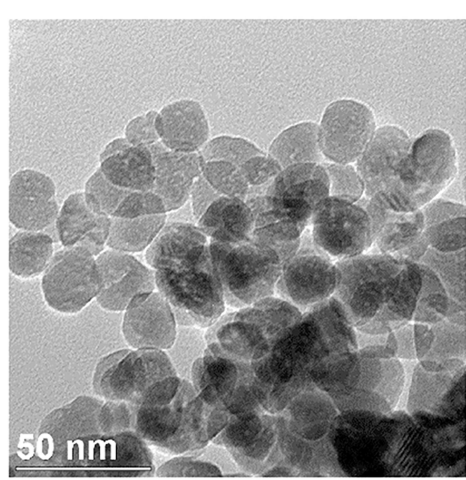

E

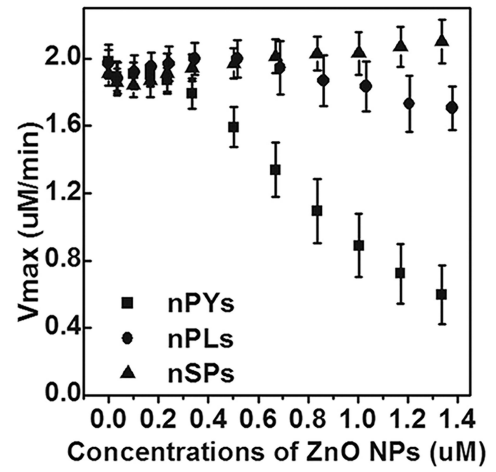

C

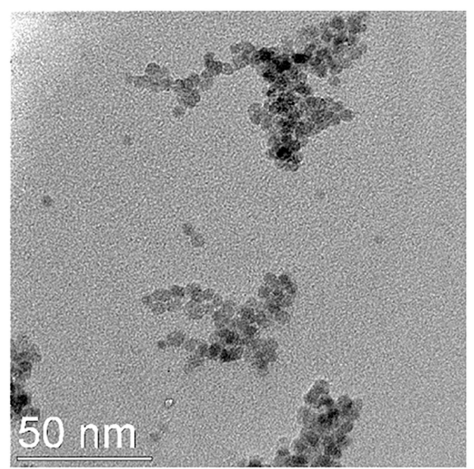

$\mathbf{F}$

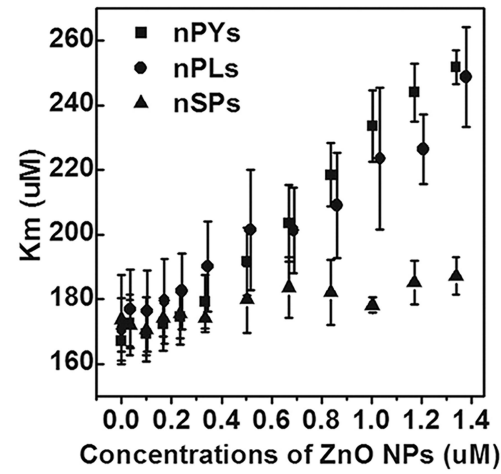

Figure 4 TEM images of ZnO (A) nanopyramids (nPYs), (B) nanoplates (nPLs), and (C) nanospheres (nSPs). (D) Relative catalytic activity of GAL in the presence of three different shaped ZnO NPs after 60 min incubation time. Each relative catalytic activity of GAL with ZnO NPs was normalized with respect to free enzyme activity. The values for (E) $V_{\max }$ and (F) $K_{m}$ of GAL were calculated from the Michaelis-Menten equation. Reprinted with permission from Cha SH, Hong J, McGuffie M et al Shape-dependent biomimetic inhibition of enzyme by nanoparticles and their antibacterial activity. ACS Nano. 2015;9(9):9097-9105. Available from: https://pubs.acs.org/doi/abs/I0.I02I/ acsnano. 5 b $03247 . .^{30}$

\section{Nanozymes as $\beta$-Galactosidase ( $\beta$ - $\mathrm{Gal}$ ) and R-Chymotrypsin (ChT) Inhibitors}

Unlike various traditional small-molecule inhibitors that target active sites, nanomaterials are more likely to act as broad-spectrum inhibitors due to their unique inhibitory mechanisms and biocompatibility. As a typical transition metal dichalcogenide, $\mathrm{MoS}_{2}$ has the ability to mimic peroxidase. ${ }^{32}$ Earlier, Karunakaran et al ${ }^{33}$ demonstrated that $\mathrm{MoS}_{2}$, after surface modification through facile thiol chemistry, could simultaneously inhibit $\beta$-Gal and ChT activity (Figure 5A). ChT contains positively charged residues around the active site that combine with negatively charged macromolecules, resulting in inhibition of enzymatic activity. Negative ligand-conjugated $\mathrm{MoS}_{2}$ exhibited high inhibitory activity for ChT (up to $90 \%$ ) at a concentration of 3 $\mu \mathrm{g} / \mathrm{mL}$. Conversely, positive $\mathrm{MoS}_{2}$ exerted limited inhibitory effects on ChT activity (Figure 5B (a) and 5B (b)). In addition, positively charged $\mathrm{MoS}_{2}$ at a concentration of 4 $\mu \mathrm{g} / \mathrm{mL}$ interacted with negatively charged $\beta$-Gal through electrostatic interactions to significantly inhibit activity $(\sim 90 \%)$ of the enzyme (Figure 5B). In contrast, neutral ligand-conjugated $\mathrm{MoS}_{2}$ exerted no significant inhibitory effects on both enzymes, even at high concentrations (Figure 5B (c) and 5B (d)).

\section{Nanozyme as $\beta$-Lactamase Inhibitors}

The discovery of penicillin in 1929 is considered a milestone in the history of medicine. ${ }^{34}$ Penicillin was successfully used as clinical treatment for bacterial infections in the 1940s. However, within a few years of using penicillin therapy, several bacterial strains began to exhibit antibiotic resistance through natural production of penicillinase. Penicillinase, also known as $\beta$-lactamase, can destroy the $\beta$-lactam ring structure of penicillin to inactivate drugs. ${ }^{35}$ Therefore, $\beta$-lactamase-controlled drug resistance poses a serious threat to the widespread clinical application of antibiotics. In this situation, development of appropriate $\beta$ - 
A

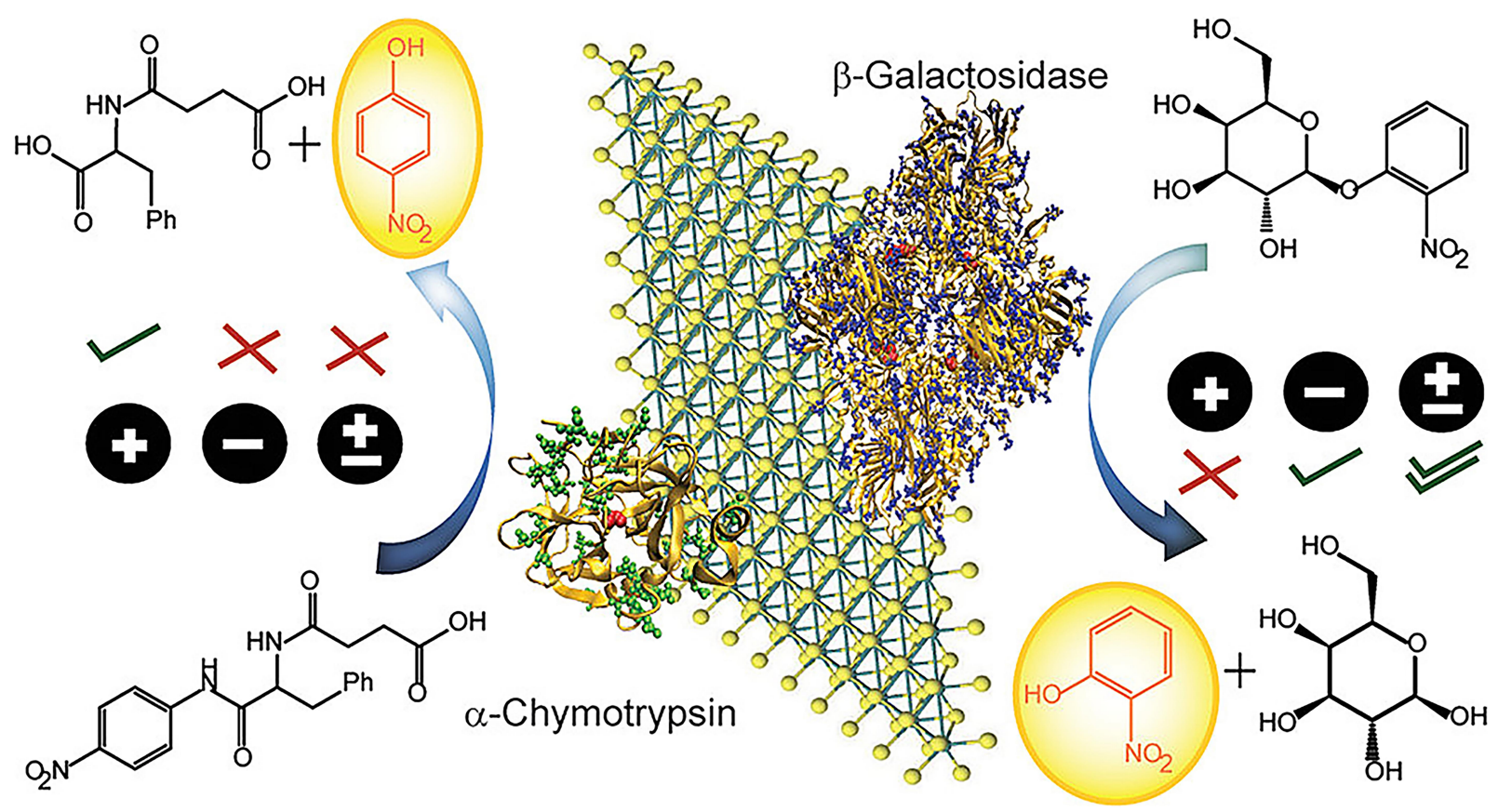

B

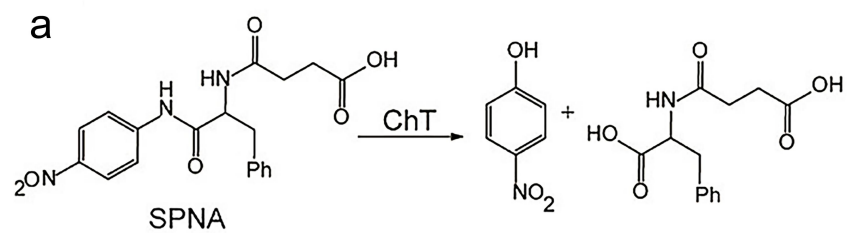

C<smiles>CC(COc1ccccc1[N+](=O)[O-])Cc1cccc(OC2OC(CO)C(O)C(O)C2OO)c1[N+](=O)[O-]</smiles><smiles>OCC1OC(O)C(O)C(O)C1O</smiles>

b

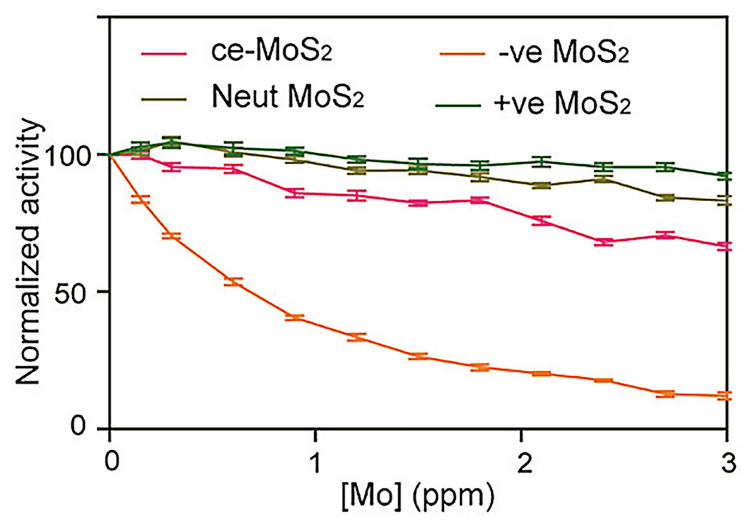

d

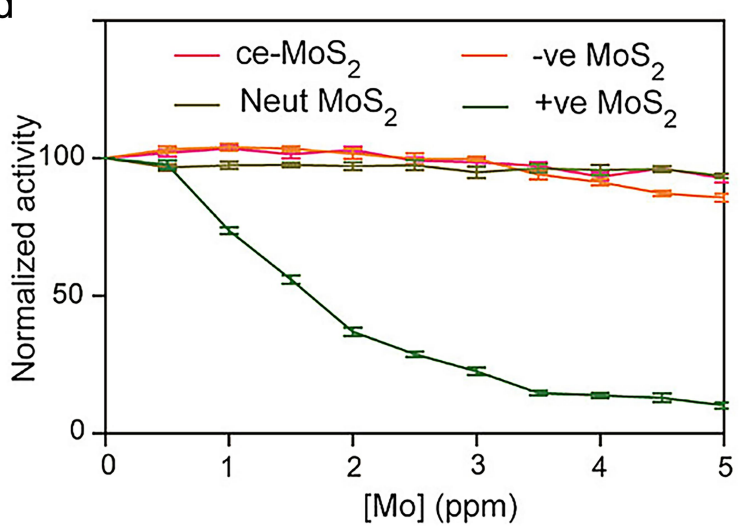

Figure 5 (A) Functionalized $\mathrm{MoS}_{2}$ interactions with different charges and different proteins. (B(a and b)) Enzymatic activity of ChT as a function of inhibitor concentrations in sodium phosphate buffer (pH 7.4) using SPNA as a substrate. The activities were normalized to that of only ChT. (c and d) Enzymatic activity of $\beta$-Gal as a function of the same inhibitor concentrations in sodium phosphate buffer ( $\mathrm{pH}$ 7.4) using o-nitrophenyl- $\beta$-D-galactopyranoside as a substrate. The activities were normalized to that of only $\beta$-gal. Reprinted with permission from Karunakaran S, Pandit S, De M. Functionalized two-dimensional MoS $_{2}$ with tunable charges for selective enzyme inhibition. ACS Omega. 2018;3(12):17532-17539. Available from: https://pubs.acs.org/doi//0.1021/acsomega.8b02598. ${ }^{33}$

lactamase inhibitors presents one of the most crucial strategies to combat multidrug-resistant bacterial infections. To date, various small-molecule inhibitors with similar structures to penicillin have been designed, such as clavulanic acid, sulbactam and tazobactam. ${ }^{36}$ However, almost all these inhibitors contain a lactam ring and cannot be used as general inhibitors due to distinct inactivation mechanisms for different types of $\beta$-lactamases. Nanomaterials have many advantages over small-molecule inhibitors as potential $\beta$-lactamases inhibitors, such as large surface area and 
surface functional modification, which significantly alter enzyme activity through multivalent interactions or steric hindrance, and display enhanced efficacy in combination with various $\beta$-lactamases.

Pandit et $\mathrm{al}^{37}$ synthesized several functionalized twodimensional molybdenum disulfide $\left(2 \mathrm{D}-\mathrm{MoS}_{2}\right)$ nanomaterials as enzyme inhibitors. The group showed that carboxylatefunctionalized negatively charged $\mathrm{MoS}_{2}$ is a potent inhibitor that effectively blocks the active site of $\beta$-lactamase and exhibits competitive inhibitory activity. The mechanism of inhibition was structurally attributed to the active center of $\beta$ lactamase being surrounded by cationic (lysine and arginine) residues (Figure 6Aa). Moreover, electrostatic interactions and steric blockage between enzymes and inhibitors additionally played an important role (Figure 6Ab). Combined antibacterial effects against methicillin-resistant Staphylococcus aureus (MRSA) using $\mathrm{MoS}_{2}$ as a $\beta$-lactamase inhibitor and ampicillin as an antibiotic were additionally evaluated. The results showed that under conditions of co-treatment of ampicillin and $\mathrm{MoS}_{2}$, growth of MRSA was inhibited with a delay in the bacterial growth rate in an $\mathrm{MoS}_{2}$ dose-dependent manner (Figure 6Ba and $\mathrm{b}$ ), indicating that in the presence of the $\beta$ lactamase inhibitor, $\mathrm{MoS}_{2}$, destruction of the antibiotic agent, ampicillin, by the MRSA bacterial strain could be prevented, resulting in delayed bacterial growth. However, in the presence of negative functionalized $\mathrm{MoS}_{2}$ only, bacterial growth was not significantly disrupted (Figure $6 \mathrm{Bc}$ ), even at a very high concentration $(25 \mu \mathrm{g} / \mathrm{mL}$; Figure $6 \mathrm{Bd})$, suggesting that $\mathrm{MoS}_{2}$ with negative ligands does not inhibit bacterial growth and is not toxic to microorganisms. This strategy combines the unique mechanisms and controllable biological activity of nanomaterials as enzyme inhibitors, providing a novel solution for clinical antibiotic resistance. Functionalized nanomaterials were more effective as combination therapy in antibacterial tests of MRSA in vitro, suggesting that enhanced inhibitory effects could be achieved by adjusting the nanomaterial surface.

Metallo- $\beta$-lactamases (MBL) represent one of the $\beta$ lactamase types that hydrolyze a broad spectrum of $\beta$-lactam antibiotics. Currently, no inhibitors that can effectively suppress enzyme hydrolysis activity are available in the clinic. ${ }^{38}$ Verona integron-encoded-2 (VIM-2), a subclass of MBLs, is a negatively charged protein with $\mathrm{Zn}^{2+}$-dependent enzyme activity. ${ }^{39}$ In a systematic investigation by Huang and coworkers, ${ }^{40}$ the effects of various nanomaterials on VIM-2 catalytic activity were explored. Among the ten nanomaterials examined with different surface properties, graphene oxide (GO) and carbon nanotube (CNT) exerted significant inhibitory effects on VIM-2 in a dose-dependent manner (Figure 7A and $\mathrm{B})$. Interestingly, this strong suppression effect contributed to hydrophobic interactions between VIM-2 and nanomaterials, but not electrostatic interactions (Figure 7C and D).
A

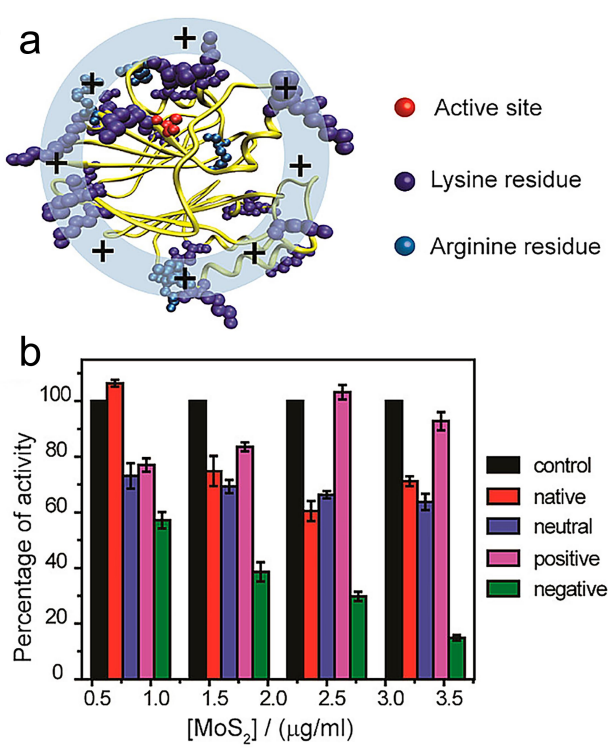

B
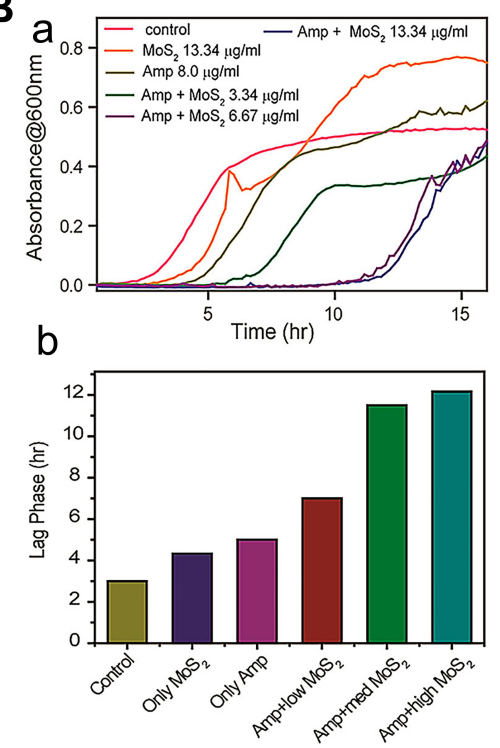

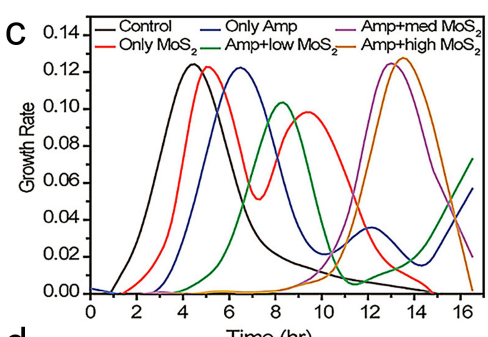

d

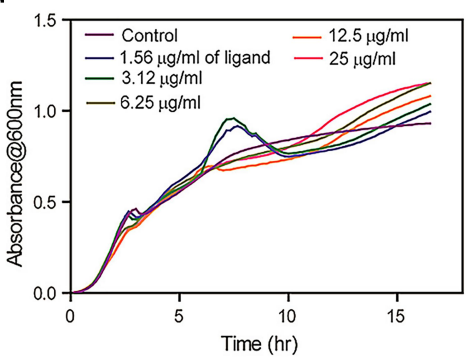

Figure $6(\mathbf{A}(\mathrm{a}))$ Structure of $\beta$-lactamase. The active site (red) of $\beta$-lactamase is surrounded by lysine and arginine (blue) residues. (b) Activity of $\beta$-lactamase in the presence of increasing concentration of various 2D MoS 2 in HEPES buffer ( $\mathrm{pH} 7.3$ ) using nitrocefin as a substrate. (B) Growth curve analysis for the bacterial strain MRSA, treated with ampicillin with various concentrations of negative functionalized $\mathrm{MoS}_{2}$ at $37^{\circ} \mathrm{C}$. (a) The bacterial growth curves over a period of $16 \mathrm{~h}$, in a real-time kinetic cycle. (b) The lag phase diagram and (c) first derivative growth rate for quantitative analysis of the growth curve. (d) Growth curve analysis for the bacterial strain MRSA, treated with various concentrations of negative ligand molecule at $37^{\circ} \mathrm{C}$ over a period of $16 \mathrm{~h}$, in a real-time kinetic cycle. Reprinted with permission from Ali SR, Pandit S, De M. 2D-MoS - -Based $\beta$-Lactamase Inhibitor for combination therapy against drug-resistant bacteria. ACS Applied Bio Materials. 2018; I(4):967-974. Copyright (2018) American Chemical Society. ${ }^{37}$ 
A

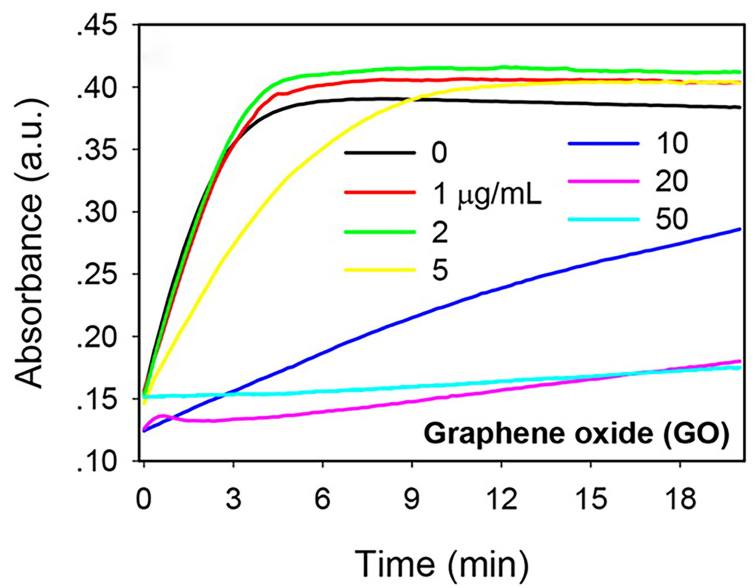

C

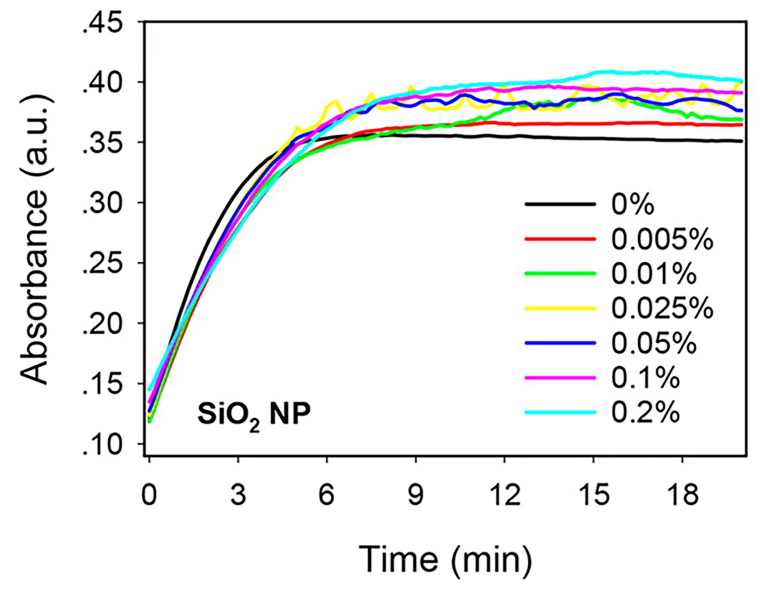

B

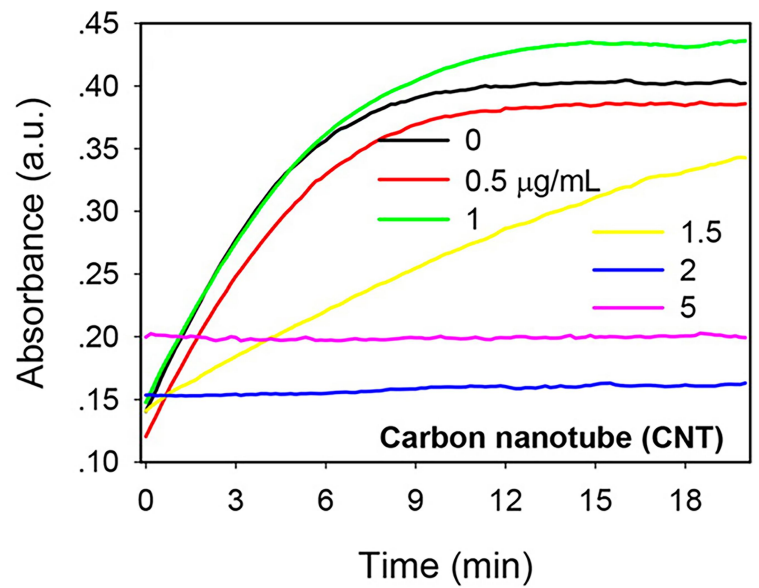

D

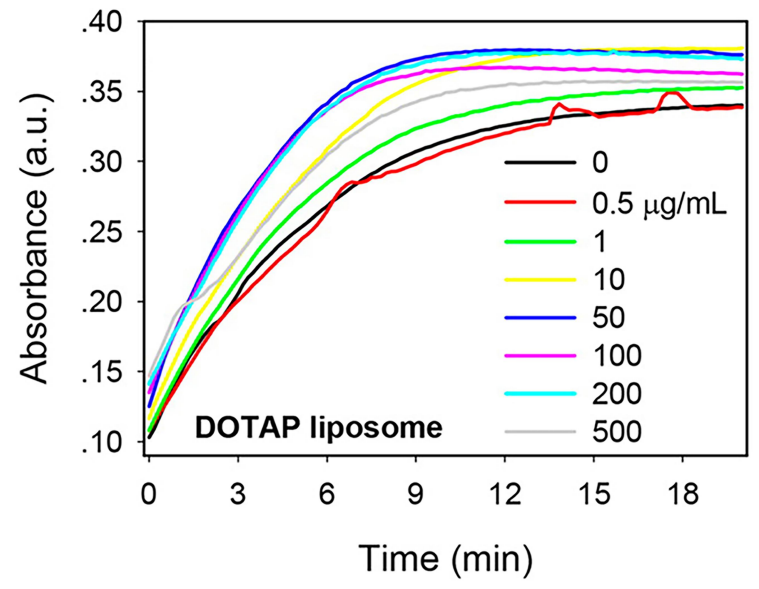

Figure 7 Kinetics of nitrocefin color change induced by VIM-2 in the presence of various concentrations of nanomaterials: (A) GO, (B) CNT, (C) $50 \mathrm{~nm} \mathrm{SiO}{ }_{2} \mathrm{NPs}$, and (D) cationic DOTAP liposomes. Reprinted with permission from Huang PJJ, Pautler R, Shanmugaraj J et al Inhibiting the VIM-2 metallo- $\beta$-lactamase by graphene oxide and carbon nanotubes. ACS Appl Mater Inter. 2015;7(18):9898-9903. Available from: https://pubs.acs.org/doi/abs//0.1021/acsami.5b01954. ${ }^{40}$

Similar to VIM-2, both GO and CNT possess hydrophobic regions that may play a key role in disrupting enzymecatalyzed reactions. Additionally, CNT exerted a more significant inhibitory effect at lower concentrations than GO. Owing to its smaller diameter, CNT fits more efficiently into the enzyme hydrophobic core. Distinct from the competitive inhibitory mechanisms of nanomaterials against ChT, GO exhibited strong non-competitive inhibition activity without inducing changes to the enzyme structure.

\section{Nanozyme as Mitochondrial FOFI-ATPase Inhibitors}

F0F1-ATPase, also known as adenosine triphosphate (ATP) synthase, participates in the synthesis of ATP to meet the high energy requirements of cells. ${ }^{41}$ ATP synthase is composed of F0-ATP synthase and F1-ATP synthase subunits. ${ }^{42} \mathrm{H}^{+}$proton flux through the F0-ATP synthase subunit drives the mechanical rotation of the $\gamma$ and $\varepsilon$ subunits within F1-ATP synthase, leading to synchronized conformational changes and production of ATP with high kinetic efficiency. ${ }^{43,44}$ Under pathological conditions (ie, hypoxia), the F0-ATP synthase subunit paradoxically hydrolyses ATP, which is responsible for causing mitochondrial dysfunction linked to cell death. $^{45-47}$ Therefore, inhibition of F0-ATP hydrolase catalytic activity plays an essential role in maintaining normal cellular metabolism, especially in conditions where mitochondrial ATP hydrolysis is exacerbated.

Carbon nanotubes (CNT) are one of most widely characterized nanomaterials with high biocompatibility and high selectivity for subcellular components, in particular, mitochondria. ${ }^{48,49}$ Michael and co-workers ${ }^{50}$ examined the potential of oxidized CNT family members to induce inhibition of mitochondrial F0-ATP hydrolase toxicity. Compared to pristine multi-walled carbon nanotubes (CNT-1) that displayed no inhibitory activity, oxidized CNT family members (CNT2-9) 
markedly suppressed F0-ATP hydrolase activity at a concentration of $5 \mu \mathrm{g} / \mathrm{mL}$. Deprotonated oxidized moieties, such as CNT-O- and CNT-COO-, could interact electrostatically with $\mathrm{H}^{+}$protons, preventing $\mathrm{H}^{+}$proton flux through F0-ATP synthase and subsequent rotation of the $\gamma$ and $\varepsilon$ subunits of F1-ATP synthase (Figure 8A). Notably, toxicological inhibition of F0ATP hydrolase induced no effects on mitochondrial membrane potential (MMP) (Figure 8B). The collective findings should promote further rational design of carbon nanomaterial structures to fulfill novel applications based on toxicological regulation and provide new opportunities for emerging research fields, such as mitochondrial nanotoxicology.

\section{Discussion}

In this report, achievements in the application of various nanomaterial-based enzyme inhibitors in recent years have been comprehensively reviewed. It is worth emphasizing that these nanomaterials possess the ability serving as both nanozymes and enzyme inhibitors (Table 1). The versatility of nanozymes has significant prospects in the field of biomedicine. However, considerable challenges remain in terms of exploring the infinite potential of nanozymes as enzyme inhibitors due to a number of reasons. (1) Most nanozyme-based inhibitors lack the specific recognition capability of traditional small-molecule inhibitors and are therefore unlikely to act selectively through electrostatic or hydrophobic

A

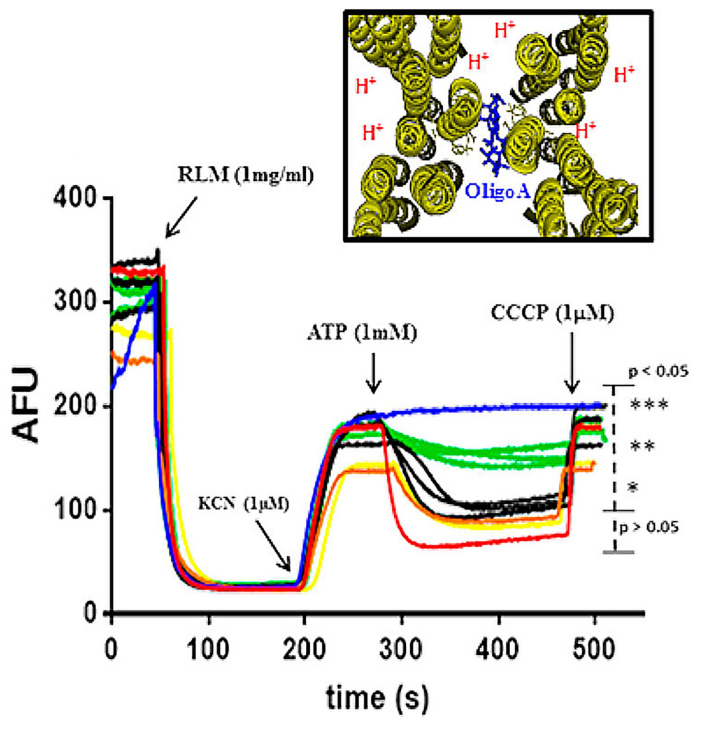

$$
\begin{aligned}
& \text { - untreated RLM (control) } \\
& \text { - RLM+DMSO (100mM) } \\
& \text { - RLM+Oligomycin A }(1 \mu \mathrm{M}) \\
& \text { - RLM+CNT1 }(5 \mu \mathrm{g} / \mathrm{ml}) \\
& \text { - RLM+CNT2 }(5 \mu \mathrm{g} / \mathrm{ml}) \\
& \text { - RLM+CNT3 }(5 \mu \mathrm{g} / \mathrm{ml}) \\
& \text { - RLM+CNT4 }(5 \mu \mathrm{g} / \mathrm{ml}) \\
& \text { - RLM+CNT5 }(5 \mu \mathrm{g} / \mathrm{ml}) \\
& \text { - RLM+CNT6 }(5 \mu \mathrm{g} / \mathrm{ml}) \\
& \text { - RLM+CNT7 }(5 \mu \mathrm{g} / \mathrm{ml}) \\
& \text { - RLM+CNT8 }(5 \mu \mathrm{g} / \mathrm{ml}) \\
& \text { - RLM+CNT9 }(5 \mu \mathrm{g} / \mathrm{ml})
\end{aligned}
$$

B
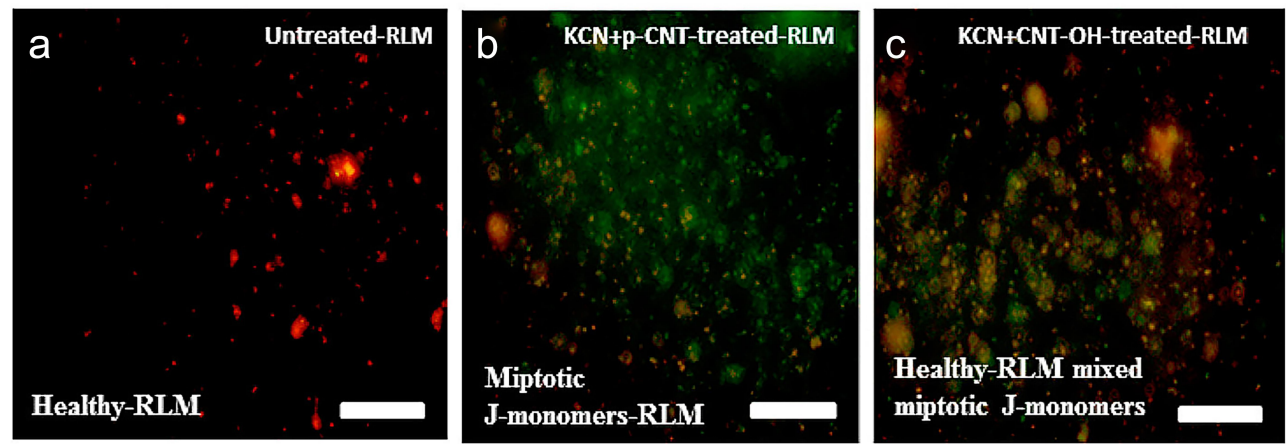

CNTs

MC)

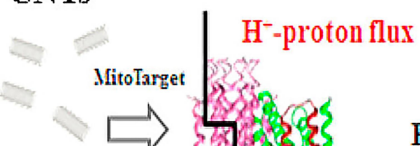

KCN-experimental ischemic conditions

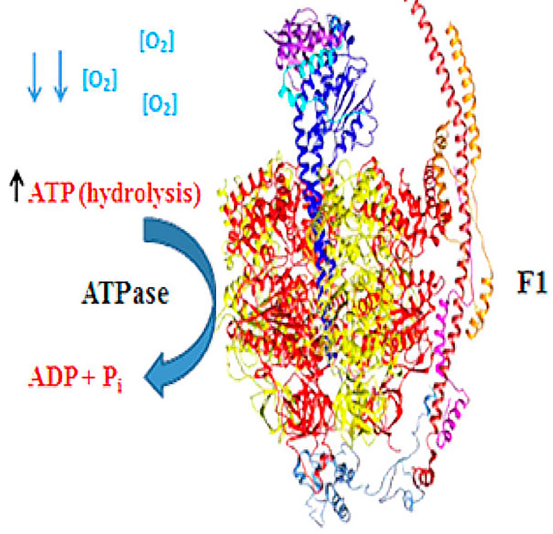

Figure $8(\mathbf{A}) \mathrm{H}^{+}$-FO-ATPase save for the pristine multi-walled carbon nanotube (CNT-I) that show low ability to induce F0-ATPase nanotoxicity-based inhibition in isolated rat liver mitochondria. (B) ATP-hydrolysis inhibition by CNT-family members at maximum concentration of $5 \mu \mathrm{g} / \mathrm{mL}$ in isolated-rat liver mitochondria (RLM). (a) UntreatedRLM (J-aggregates: red fluorescence); (b) KCN+p-CNT-treated-RLM (miptotic J-monomers: green fluorescence); (c) KCN+CNT-OH (CNT2-CNT5) treated-RLM (J-aggregates mixed miptotic J-monomers: red to pseudo-colored red fluorescence); (d) KCN+CNT-COOH (CNT6-CNT9) treated-RLM (J-aggregates: red fluorescence). Reprinted with permission from González-Durruthy M, Manske Nunes S, Ventura-Lima J et al Mitotarget modeling using ANN-classification models based on fractal SEM nano-descriptors: Carbon nanotubes as mitochondrial FOFI-ATPase inhibitors. J Chem Inf Model. 2019;59(1):86-97. Copyright (2018) American Chemical Society. ${ }^{50}$ 
Table I Summary of Nanozymes as Both Enzymes and Enzyme Inhibitors

\begin{tabular}{|c|c|c|c|c|}
\hline Nanozymes & As Enzyme Mimics & $\begin{array}{l}\text { As Enzyme } \\
\text { Inhibitors }\end{array}$ & Inhibition Mechanism & Applications \\
\hline $\mathrm{Au} \mathrm{NPs}{ }^{21,23}$ & $\begin{array}{l}\text { Peroxidase-, oxidase-, and } \\
\text { glucose oxidase-like activities }\end{array}$ & $\mathrm{ChT}$ & Electrostatic interactions & Protein interaction \\
\hline $\mathrm{GO}^{26}$ & \multirow[t]{6}{*}{ Peroxidase-like activity } & $\mathrm{ChT}$ & Hydrophobic interaction & Protein surface recognition \\
\hline $\mathrm{ZnO} \mathrm{NPs}^{30}$ & & $\beta-G a l$ & $\begin{array}{l}\text { Hydrogen bonding, Vender Waals } \\
\text { force, Molecular shape }\end{array}$ & $\begin{array}{l}\text { Occurrence of primary ovarian } \\
\text { cancer and cell aging }\end{array}$ \\
\hline $\mathrm{MoS}_{2}{ }^{33}$ & & $\begin{array}{l}\beta-G a l \text { and } \\
\text { ChT }\end{array}$ & Electrostatic interactions & Disease diagnosis and treatment \\
\hline $2 \mathrm{D}-\mathrm{MoS}_{2}{ }^{37}$ & & $\beta$-lactamase & $\begin{array}{l}\text { Electrostatic interactions and } \\
\text { steric blockage }\end{array}$ & $\beta$-lactamase antibiotic resistance \\
\hline $\mathrm{GO}$ and $\mathrm{CNT}^{40}$ & & MBLs & Hydrophobic interaction & $\begin{array}{l}\text { Inhibit the hydrolysis of broad- } \\
\text { spectrum } \beta \text {-lactam antibiotics }\end{array}$ \\
\hline $\mathrm{CNTs}^{50}$ & & FOFI-ATPase & Electrostatic interactions & Mitochondrial dysfunction \\
\hline
\end{tabular}

Abbreviations: AuNPs, gold nanoparticles; GO, graphene oxide; ZnO NPs, ZnO nanoparticles; CNTs, carbon nanotubes; ChT, R-chymotrypsin; $\beta$-Gal, $\beta$-galactosidase; MBLs, metallo- $\beta$-lactamases.

interactions. Once the surface of nanomaterials is blocked by other proteins, their activity as inhibitors of target enzymes is markedly reduced. (2) A considerable number of targets exist mainly in the form of intracellular enzymes (although they can also be released into the surrounding medium) and in order to effectively inhibit enzyme activity, nanomaterials need to cross the cell membrane, which is a key challenge in the development of effective enzyme inhibitors. (3) The longterm safety of nanomaterials remains to be ascertained. Further studies focused on optimizing and improving the structures of nanozymes are therefore warranted to improve their specificity and explore potential novel applications.

\section{Acknowledgments}

This project was funded by the National Natural Science Foundation of China (No. 21703198). The authors also gratefully acknowledge financial support from the Priority Academic Program Development of Jiangsu Higher Education Institutions and High-Level Talent Support Plan of Yangzhou University.

\section{Disclosure}

The authors declare that there is no conflict of interest in this work.

\section{References}

1. Blow DM. Structure and mechanism of chymotrypsin. Accounts Chem Res. 1976;9(4):145-152. doi:10.1021/ar50100a004

2. Sun SJ, Chen YT, Liu Q, et al. Alpha-glucosidase inhibitor for the treatment of diabetes. Acta Pharmacol Sin. 2006;27:306.

3. Guarnieri F, Spencer JL, Lucey EC, et al. A human surfactant peptide-elastase inhibitor construct as a treatment for emphysema. P Natl Acad Sci USA. 2010;107(23):10661-10666. doi:10.1073/ pnas. 1001349107

4. Brunet C, Jegaden M, Darque A, et al. Anticholinesterase inhibitors in Alzheimer's disease: follow-up of a cohort since 1994. Pharm World Sci. 2009;31(2):272-273.

5. Dorai T, Aggarwal BB. Role of chemopreventive agents in cancer therapy. Cancer Lett. 2004;215(2):129-140. doi:10.1016/j. canlet.2004.07.013

6. Fujimoto T, Matsushita Y, Gouda $\mathrm{H}$, et al. In silico multi-filter screening approaches for developing novel beta-secretase inhibitors. Bioorg Med Chem Lett. 2008;18(9):2771-2775. doi:10.1016/j. bmcl.2008.04.011

7. Wang Z, Kwon SH, Hwang SH, et al. Competitive binding experiments can reduce the false positive results of affinity-based ultrafiltration-HPLC: a case study for identification of potent xanthine oxidase inhibitors from Perilla frutescens extract. $J$ Chromatogr $\quad$ B. 2017;1048:30-37. doi:10.1016/j. jchromb.2017.02.001

8. Parish EJ, Honda H, Lo YC, et al. New approaches to the chemical synthesis of citronellol type compounds useful as enzyme inhibitors. Abstr Pap Ame. 2012;243:7.

9. Branchini BR. Chemical synthesis of firefly luciferin analogs and inhibitors. J Biolum Chemilum. 2000;305:188-195.

10. Adjei AA. What is the right dose? The elusive optimal biologic dose in Phase I clinical trials. J Clin Oncol. 2006;24(25):4054-4055. doi:10.1200/JCO.2006.07.4658

11. Fan KL, Xi JQ, Fan L, et al. In vivo guiding nitrogen-doped carbon nanozyme for tumor catalytic therapy. Nat Commun. 2018;9(1):1440. doi:10.1038/s41467-018-03903-8 
12. Gao LZ, Fan KL, Yan XY. Iron Oxide Nanozyme: a multifunctional enzyme mimetic for biomedical applications. Theranostics. 2017;7 (13):3207-3227. doi:10.7150/thno.19738

13. Cormode DP, Gao LZ, Koo H. Emerging biomedical applications of enzyme-like catalytic nanomaterials. Trends Biotechnol. 2018;36 (1):15-29. doi:10.1016/j.tibtech.2017.09.006

14. Wu J, Lv W, Yang Q, et al. Label-free homogeneous electrochemical detection of MicroRNA based on target-induced anti-shielding against the catalytic activity of two-dimension nanozyme. Biosens Bioelectron. 2021;171:112707. doi:10.1016/j. bios.2020.112707

15. Zhang T, Tian F, Long L, et al. Diagnosis of rubella virus using antigen-conjugated $\mathrm{Au} @ \mathrm{Pt}$ nanorods as nanozyme probe. Int J Nanomedicine. 2018;13:4795-4805. doi:10.2147/IJN.S171429

16. Wang $\mathrm{X}, \mathrm{Lv} \mathrm{W}, \mathrm{Wu} \mathrm{J}$, et al. In situ generated nanozyme-initiated cascade reaction for amplified surface plasmon resonance sensing. Chem Commun. 2020;56(33):4571-4574. doi:10.1039/d0cc01117g.w

17. Cassidy CS, Lin J, Frey PA. A new concept for the mechanism of action of chymotrypsin: the role of the low-barrier hydrogen bond. Biochemistry. 1997;36(15):4576-4584. doi:10.1021/bi962013o

18. Groves K, Wilson RJ, Hamilton AD. Catalytic unfolding and proteolysis of cytochrome c induced by synthetic binding agents. $J \mathrm{Am}$ Chem Soc. 2004;126(40):12833-12842. doi:10.1021/ja0317731

19. Baugh SDP, Yang Z, Leung DK, et al. Cyclodextrin dimers as cleavable carriers of photodynamic sensitizers. $J$ Am Chem Soc. 2001;123(50):12488-12494. doi:10.1021/ja011709o

20. Liu B, Liu J. Surface modification of nanozymes. Nano Res. 2017;10 (4):1125-1148. doi:10.1007/s12274-017-1426-5

21. You CC, De M, Han G, et al. Tunable inhibition and denaturation of $\alpha$-Chymotrypsin with amino acid-functionalized gold nanoparticles. J Am Chem Soc. 2005;127(37):12873-12881. doi:10.1021/ ja0512881

22. Xi JQ, Wang WJ, Da LY, et al. Au-PLGA hybrid nanoparticles with catalase-mimicking and near-infrared photothermal activities for photoacoustic imaging-guided cancer therapy. ACS Biomater Sci Eng. 2018;4(3):1083-1091. doi:10.1021/acsbiomaterials.7b00901

23. You CC, Agasti SS, De M, et al. Modulation of the catalytic behavior of $\alpha$-Chymotrypsin at monolayer-protected nanoparticle surfaces. $J$ Am Chem Soc. 2006;128(45):14612-14618. doi:10.1021/ja064433z

24. Raina K, Crews CM. Targeted protein knockdown using small molecule degraders. Curr Opin Chem Biol. 2017;39:46-53. doi:10.1016/j. cbpa.2017.05.016

25. Song YJ, Chen Y, Feng LY, et al. Selective and quantitative cancer cell detection using target-directed functionalized graphene and its synergetic peroxidase-like activity. Chem Commun. 2011;47 (15):4436-4438. doi:10.1039/c0cc05533f

26. De M, Chou SS, Dravid VP. Graphene oxide as an enzyme inhibitor: modulation of activity of $\alpha$-Chymotrypsin. J Am Chem Soc. 2011;133 (44):17524-17527. doi:10.1021/ja208427j

27. Wang Y, Li SS, Yang HY, et al. Progress in the functional modification of graphene/graphene oxide: a review. RSC Adv. 2020;10 (26):15328-15345. doi:10.1039/d0ra01068e

28. Zhang J, Cheng P, Pu K. Recent advances of molecular optical probes in imaging of $\beta$-Galactosidase. Bioconjugate Chem. 2019;30 (8):2089-2101. doi:10.1021/acs.bioconjchem.9b00391

29. Holleran WM, Ginns E, Menon G, et al. Consequences of beta-glucocerebrosidase deficiency in epidermis. Ultrastructure and permeability barrier alterations in Gaucher disease. J Clin Invest. 1994;93:1756-1764. doi:10.1172/JCI117160
30. Cha SH, Hong J, McGuffie M, et al. Shape-dependent biomimetic inhibition of enzyme by nanoparticles and their antibacterial activity. ACS Nano. 2015;9(9):9097-9105. doi:10.1021/ acsnano. 5 b03247

31. Tripathi RM, Ahn D, Kim YM, et al. Enzyme mimetic activity of $\mathrm{ZnO}-\mathrm{Pd}$ nanosheets synthesized via a green route. Molecules. 2020;25(11):2585. doi:10.3390/molecules 25112585

32. Zhao K, Gu W, Zheng SS, et al. SDS- $\mathrm{MoS}_{2}$ nanoparticles as highly-efficient peroxidase mimetics for colorimetric detection of $\mathrm{H}_{2} \mathrm{O}_{2}$ and glucose. Talanta. 2015;141:47-52. doi:10.1016/j. talanta.2015.03.055

33. Karunakaran S, Pandit S, De M. Functionalized two-dimensional $\mathrm{MoS}_{2}$ with tunable charges for selective enzyme inhibition. ACS Omega. 2018;3(12):17532-17539. doi:10.1021/acsomega. $8 \mathrm{~b} 02598$

34. Bennett JW, Chung KT. Alexander Fleming and the discovery of penicillin. Adv Appl Microbiol. 2001;49:163-184.

35. Taubes G. The bacteria fight back. Science. 2008;321 (5887):356-361. doi:10.1126/science.321.5887.356

36. Bebrone C, Lassaux P, Vercheval L, et al. Current challenges in antimicrobial chemotherapy. Drugs. 2010;70(6):651-679. doi: $10.2165 / 11318430-00000000-00000$

37. Ali SR, Pandit S, De M. $2 \mathrm{D}-\mathrm{MoS}_{2}$-based $\beta$-lactamase inhibitor for combination therapy against drug-resistant bacteria. ACS Appl Bio Mater. 2018;1(4):967-974. doi:10.1021/acsabm.8b00105

38. Cornaglia G, Giamarellou H, Rossolini GM. Metallo- $\beta$-lactamases: a last frontier for $\beta$-lactams? Lancet Infect Dis. 2011;11(5):381-393. doi:10.1016/S1473-3099(11)70056-1

39. Poirel L, Naas T, Nicolas D, et al. Characterization of VIM-2, a carbapenem-hydrolyzing metallo-beta-lactamase and its plasmidand integron-borne gene from a pseudomonas aeruginosa clinical isolate in France. Antimicrob Agents Ch. 2000;44:891-897. doi:10.1128/AAC.44.4.891-897.2000

40. Huang PJJ, Pautler R, Shanmugaraj J, et al. Inhibiting the VIM-2 metallo- $\beta$-lactamase by graphene oxide and carbon nanotubes. ACS Appl Mater Inter. 2015;7(18):9898-9903. doi:10.1021/ acsami.5b01954

41. Oster G, Wang HY. Rotary protein motors. Trends Cell Bio. 2003;13 (3):114-121. doi:10.1016/s0962-8924(03)00004-7

42. Champagne E, Martinez LO, Collet X, et al. Ecto-F1F0 ATP synthase/F-1 ATPase: metabolic and immunological functions. Curr Opin Lipidol. 2006;17(3):279-284. doi:10.1097/01.mol.00002 26120.27931.76

43. Junge W, Sielaff H, Engelbrecht S. Torque generation and elastic power transmission in the rotary F0F1-ATPase. Nature. 2009;459 (7245):364-370. doi:10.1038/nature08145

44. Fillingame R, Jiang W, Dmitriev OY. Coupling $\mathrm{H}^{+}$transport to rotary catalysis in F-type ATP synthases: structure and organization of the transmembrane rotary motor. $J$ Exp Bio. 2000;203:9-17.

45. Atwal KS, Ahmad S, Ding CZ, et al. N-[1-Aryl-2-(1-imidazolo) ethyl]-guanidine derivatives as potent inhibitors of the bovine mitochondrial F1F0 ATP hydrolase. ChemInform. 2003;4(23):1027-1030. doi:10.1002/chin.200423143

46. Shchepina L, Pletjushkina O, Avetisyan A, et al. Oligomycin, inhibitor of the F-0 part of H+-ATP-synthase, suppresses the TNF-induced apoptosis. Oncogene. 2002;21:8149-8157. doi:10.1038/sj.onc. 1206053 
47. Atwal KS, Wang P, Rogers WL, et al. Small molecule mitochondrial F1F0 ATPase hydrolase inhibitors as cardioprotective agents. Identification of 4-(N-Arylimidazole)-substituted benzopyran derivatives as selective hydrolase inhibitors. J Med Chem. 2004;47 (5):1081-1084. doi:10.1021/jm030291x

48. Yang Z, Zhang Y, Yang Y, et al. Pharmacological and toxicological target organelles and safe use of single-walled carbon nanotubes as drug carriers in treating Alzheimer disease. Nanomed- Nanotechnol. 2010;6:427-441. doi:10.1016/j. nano.2009.11.007
49. Liu J, Yuan B, Wu X, et al. Modulated enhancement in ion transport through carbon nanotubes by lipid decoration. Carbon. 2017;111:459-466. doi:10.1016/j.carbon.2016.10.030

50. González-Durruthy M, Manske Nunes S, Ventura-Lima J, et al. Mitotarget modeling using ANN-classification models based on fractal SEM nano-descriptors: carbon nanotubes as mitochondrial F0F1-ATPase inhibitors. J Chem Inf Model. 2019;59(1):86-97. doi:10.1021/acs.jcim.8b00631

\section{Publish your work in this journal}

The International Journal of Nanomedicine is an international, peerreviewed journal focusing on the application of nanotechnology in diagnostics, therapeutics, and drug delivery systems throughout the biomedical field. This journal is indexed on PubMed Central, MedLine, CAS, SciSearch ${ }^{\mathbb{R}}$, Current Contents ${ }^{\mathbb{R}} /$ Clinical Medicine,
Journal Citation Reports/Science Edition, EMBase, Scopus and the Elsevier Bibliographic databases. The manuscript management system is completely online and includes a very quick and fair peer-review system, which is all easy to use. Visit http://www.dovepress.com/ testimonials.php to read real quotes from published authors. 